\title{
Maxillofacial surgery and Napoleonic Great Army
}

\section{Xavier Riaud* \\ Dental Surgery, National Academy of Dental Surgery, France}

\section{Introduction}

There is few information about maxillofacial surgery during Napoleon's epic. The most essential part is the precepts provided by Dominique Larrey.

"One must remember that during Napoleon's period, the critically wounded were killed on the battle field to end their suffering and to avoid palliative and curative treatments which would have delayed the troops' progression. Whatever the nature of the injuries was, the wounded were more highly likely to die from epidemics. Napoleon advocated for vaccine prevention. The former was particularly sensitive to the treatment aimed at protecting more the combatant than the man [1]."

There was no dentist within Napoleon's army. The military surgeons were in charge of dental surgery on the front $[2,3]$. They treated the ailing soldiers' dental diseases with shoemaker pliers $[4,5]$. (Figures 1 and 2)

Head surgeon of Napoleon's Great Army in 1812, he played a part in all the Grande Armée's campaigns: that is to say 25 campaigns, 200 confrontations, 40 battles. He was wounded six times on the battlefield [8]. He was the first to receive the qualification of doctor in surgery [9]. Officer of the Legion of Honour in 1804, Napoleon appointed him commander in Eylau in 1807 on the battlefield, member of the Royal Academy of Medicine in 1820, of the Academy of Sciences in 1829, he was appointed Baron of the Empire in 1809 [8,10].

"I pay tribute to eternal honour and loyalty".

In 1793, Larrey invented three types of needles to suture neck and facial wounds, which earned him the gold medal of the Academy

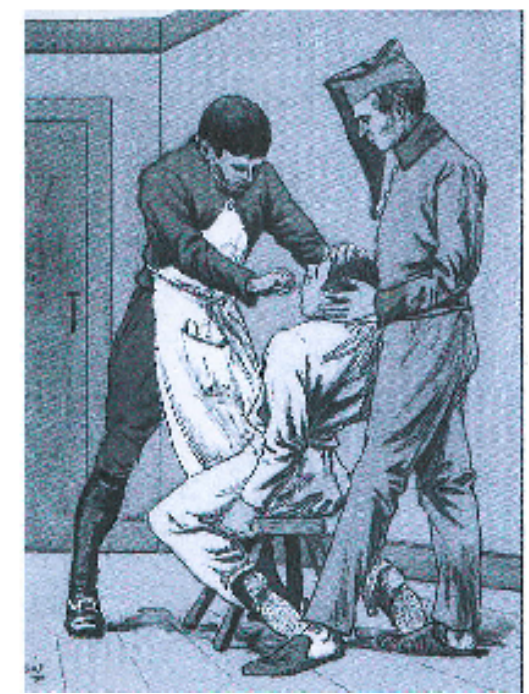

Figure 1. Student in surgery and surgeon with surgical clothing, 1805 [6].

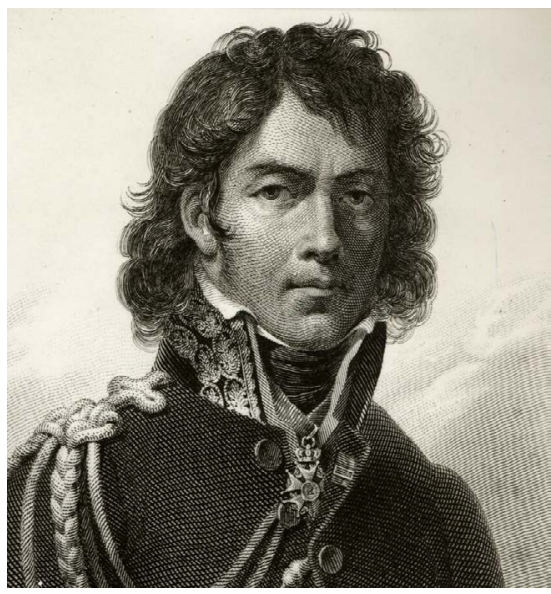

Figure 2. Dominique Jean Larrey (1766-1842), [7]

of Surgery. From then on, he was always present on the battlefield alongside the soldiers. He was extremely strict regarding cleaning and hygiene standards and thus, everyday he used to rub his body with vinegary water.

In 1794, upon his return to Paris, his system of ambulance volantes ("flying ambulances") was unanimously hailed by the public welfare committee [11,12]. In 1795, he was a professor in l'Ecole de santé du Val-de-Grâce where he gave lectures on anatomy and operative medicine (Gourdol et al. [13] stated that he taught anatomy and military surgery and that he was named the inaugural chair holder). In 1801, while Alexandria was besieged by the British forces, there was an outbreak of scurvy. Larrey recommended hygiene and dietary measures which eradicated all the symptoms. Ultimately, he mourned the loss of only a few men [8]. In 1805, he visited the hospitals of Vienna and implemented very strict hygiene measures to eradicate all epidemics [8]. In 1806, in Jena, Larrey initiated the wounded's selection according to the severity of their condition [11,12]. In Wagram, in 1809, he used cold to anaesthetize the injured and undertook to evacuate as soon as possible to avoid wound infections [8]. "It is thanks to Larrey that the system of the wounded's sorting and classification, in order of urgency during their massive arrival, was initiated [8]..., a classification which was still in effect during the $20^{\text {th }}$ century, notably during the two world wars.

*Correspondence to: Xavier Riaud, Associate professor of Dental Surgery, National Academy of Dental Surgery, France, Tel: 0240766488; E-mail: xavier.riaud@wanadoo.fr

Received: August 31, 2018; Accepted: September 12, 2018; Published: September 15, 2018 


\section{An episode}

After having listed all the elements that may contribute to the improvement of treatment and recovering conditions for facial injuries, here are testimonies explaining the protocols used. Dr André Soubiran ${ }^{1}$ (1966) [14] dated this episode back to August 24, 1812 whereas Dr. Jean Marchioni [8], dated it back to July $26^{\text {th }}$ of the same year. I would tend towards Dr Marchioni's researches as they were based from Larrey's memoirs and many other original documents which belonged to him. Dominique Larrey related: "A Russian colonel, one of the first who had been brought to the hospital, had received from one of our cavalrymen a sabre thrust which had cut his nose from the bottom along its full length. On one hand, we could see the full stretch of the nasal and mouth cavities, without any alveolar arch; and on the other, the flap of the whole nose, upper mouth and the hard palate was inverted on the chin."

The surgeon added: "I struggled to remove blood clots which were filling the nasal cavities and which the dust had made visible. Then, I removed the part of the hard palate which was hanging from the flap. It was made up of the front half of the upper alveolar arch. It had been separated from the rest of the jaw, between the canine tooth and the first molar on one side, and between the first two molars on the other. From the flap, I also untied several parts of the bones belonging to the nose and rising apophyses of the maxillary bones. I put the nose and the lip side by side again, then I linked them with intersected stitches, beginning with the nose root and going down one after the other on its two sides, whose edges were reunited thanks to ten parallel stitches."

Finally, Larrey concluded: "I applied a thin cloth, which I had soaked in salty water, on the whole triangle which indicated where the wound was. In the nostrils, I introduced two portions of big rubber-elastic probes to keep its shape and diameter. They were hold in place on the outside thanks to a thread which I had passed through their front end. I applied graduated compresses on both sides of the nose and then, a retentive bandage. Upon my return from Moscow, I was pleased to learn that this senior officer was perfectly cured without deformity."

\section{Surgical procedures}

According to Karine Ferret-Dussart [9], there were "passages concerning facial wounds in Larrey's memoirs."

- For all facial wounds, whatever their scope was, Larrey [15] recommended "immediate stiches". "Immediate stiches allow to draw near the edges of the wound more easily, notably on the face and thus, to diminish difformities".

As for major facial disrepair with consequent loss of soft tissues, Larrey always sutured the wound after wrapping the thread in the shape of an 8 around a needle and going through the two edges of the wound from end to end. This ensured a stronger stitch $[9,15]$.

"During the Egyptian campaign, General Verdier's aide-de-camp was shot to the mouth by mean of a pistol shot. It completely removed his left cheek, from the corners of the mouth to the masseter, so that the two alveolar archs, the tongue and a part of its muscles were uncovered. The edges of the wound were upside down and blackish; the officer had considerable pain. I hurried to refresh the flaps, to regularise the wound by binding the lips perfectly to it and I fixed them with nine interspersed stitches, and an appropriate retentive bandage. The wounded soldier was placed on a controlled reducing diet. He could use refreshments to avoid fever and other medical problems. The treatment only lasted seventeen days and there were very few difformities [15]."

1. Témoignage relaté par Soubiran également dans l'article « Une horrible opération », in Revue de la Société française d'histoire de l'art dentaire, 1978 : 1: 20.
- According to Karine Ferret-Dussart [9], as for fractured facial wounds, Larrey patiently removed all the bone splinters. Then he narrowed the fracture. Finally, with dental ligations carried out thanks to gold or platinum threads, or by means of an intraoral gutter and a chinstrap, he immobilised the jawbone. Unfortunately, this method was unsuccessful as the aftereffects were recurrent $[9,15]$.

- Karine Ferret-Dussart [9] added: "For wounds of smaller scope, Larrey sutured the wound and used a rubber-elastic probe to shape the nostrils. Rhinopoiesis by means of neighbouring flaps was successfully carried out by Larrey by 1820."

On reading Larrey's testimony, he obviously seemed to master the technique and the result seems convincing. Larrey was confident, pragmatic and a technical man.

"At the end of the year 1820, one of my former students and worthy companions from Egypt, doctor Zink, surgeon-major at the Hospital de Givet, sent me a noncommissioned officer of the Aude legion. He was afflicted with a horrible deformity and an unbearable look, coming from a gunshot that he had given himself in a fit of melancholy eighteen months before [16]."

(...) All the palate of the maxillary bones which was originally between the upper canine teeth was removed; the nasal labyrinthine portions, the nasal bones, and the nasal cartilages were destroyed or removed. The two nasal wings were retroverted outwards and backwards; the lower septum was now part of the left nostril.

This wound was bandaged like any other gunshot wounds, that is to say with emollients and a retentive device; it went through suppuration, a detersive cleaning phase until healing without after-effects. It spontaneously healed. The edges closely bonded with the outer surface of the upright apophysis, in such a way as to produce a red, uneven, repellent, cavernous notch on the face. His sense of smell was paralyzed. He could not chew or talk well; he could barely utter the simplest words.

Such was this sergent's state of mind when he introduced himself at the Royal Guard's hospital, in December 1820. (...) I carefully examined him, I planned to perform surgery on him and I immediately informed my assistants, and without wasting time, I put this surgical plan into action.

Assisted by Doctor Rives (...), the patient seated on a chair, I started to remove the tegumentary and adhesive edges around the entire circumference of this horrible wound or notch; I then dissected several extended lines towards the cheekbones, on the area of the maxillary bones, in order to get a rather big stretch of skin to cross the space between the edges of this cut, and to bond them once in contact with one another [16].

Then, I removed the adhesions that the two divisions of the nasal wings and the upper lip had contracted with the edges of the palatal notch. This dissection was long and hard to perform. After having singled out all the soft tissues which had previously belonged to the nose, I refreshed the edges in a uniform way thanks to sharp surgical scissors in order to give to each cut the shape it was supposed to have.

One this dissection was done, I performed three temporary stitches: the first was in the middle of the nose bone; the second at the top of this eminence and towards the lower septum of the nostrils that I had kept; the third, at the two edges of the upper lip. I then bonded and attached the soft tissues of the entire nasal back with pegged stitches made up of six elliptical threads in order to bring together the tissues which were meant to shape this organ, and to prevent any cuts which might have occurred if I had performed interspersed stitches. Finally, I attached the excised 
edges of the lip and the loose edges of the jaw by means of twisted stitches performed with two gold sharp-edged needles.

Once this was done, I applied a retentive bandage, full of graduated compresses to protect the various stitches. The patient was placed on a diet. He could use refreshing, mucilaginous and anti-spasmodic refreshments (...). Upon the ninth day after the surgery, I removed the bandage and to my great surprise, all the sutured edges were perfectly bonded and healed; however, I left the surgical pegs and dowels in place until the fifteenth day, when I removed them all.

The healing was accurate, consistent and linear and we could notice that the wound had obviously healed thanks to the natural alignment of the vessels belonging to the edges of this enormous wound. In the interstices, it was impossible to detect the tiniest part of gelatinous substance which did not correspond to these vessels. Finally, the healing was perfect, and the nose took on a rather regular shape so much so that the patient's physionomy was no longer appalling. His speech, pronunciation and chewing improved greatly; the substantial gap between the maxillary bones and in the sides of the nasal cavities tightened; this would keep on narrowing, so that the features of the face would become more and more regular [16]."

Do we master surgical techniques that we only performed once? Can we make such a detailed and accurate account only after having performed once this sort of surgical procedure? I highly doubt it. On the contrary, I am convinced that Larrey, as he was writing these lines, had already carried out numerous interventions of facial reconstruction, given his responsibilities, with similar procedures and very high success rates. This is why I was keen to use the testimony dating back to 1820 whereas the Empire collapsed in 1815. Even though there is no real evidence, it is highly likely that Larrey performed these techniques on the battlefields during the Napoleonic Wars. (Figure 3)

In 1793, in Lauterbourg, General Desaix received a bullet which crossed his two cheeks. As he was unable to talk, he carried on his command with gestures to his men who were panicking. He did not leave the battlefield to get a bandage until his soldiers were all rallied under his command. His face was said to be "stitched with scars (...) hastily mended by makeshift surgons" [17].

During the battle of Abukir, on July 25, 1799, when capturing pasha Mustapha, Joachim Murat received a bullet which crossed the jaw from one end to the other. Luckily, his tongue was left untouched: his mouth was opened at that time. "It's the first time that he relevantly opened it", commented his chief. "This wound did not leave many traces, but it could be visible on Wicar's portrait" (1808). We can see a highly rolled up collar. However, another wound hurt him more. In 1803, in Milan, a hunting accident or a firing exercise which had gone wrong because

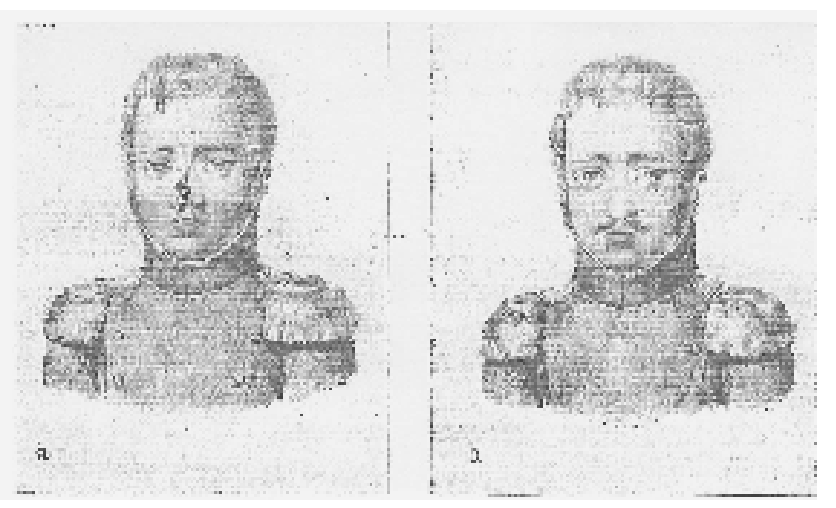

Figure 3. Rhinoplasty according to Dominique Larrey's method (before (a) - after (b)) [6] of a defective or improperly cleaned firearm, paralyzed his upper lip. "A medical certificate given by the garrison doctor, reported the paralysis of the general's upper lip following a gunshot that he had received [18]". As for facial wounds, here are surgical recommendations [8]:

Head and neck injuries $>>>$ Use of trephine.

Facial open wounds $>>$ Immediate stitches (wound closure as soon as possible).

No anaesthesia $\gg>>$ Surgeon's surgical speed and skill, two glasses of hooch (sometimes), and laudanum (exceptional). Fever $\gg>$ A glass of rum, juice of 2 lemons with a spoonful of salt and pepper. Sometimes cinchona depending on the supply (origin: America).

\section{Conclusion}

It should be noted that the teeth of the 50,000 French soldiers who died on the battlefield in Waterloo were extracted to make naturalteeth dentures for the English nobility. One of them is still exhibited in London [19]. They were nicknamed "Waterloo's teeth".

\section{References}

1. Long François-Xavier (2002) Facial injured soldiers during the Great War: the origins of maxillofacial surgery. Journal of History of Medical Sciences 36: 175-183.

2. Lecomte O, Tristan D (2010) The practitioners of the armies in the history of dentistry. Medicine and armies 38: 469-476.

3. Riaud Xavier (2016) Medicine throughout the centuries Collection. Paris.

4. Sandeau Jacques (2004) Health in the armies. The organisation of the Service and the hospitals. Great figures and harsh realities (part one). Review of Napoleonic Remembrance 450: 19-27.

5. Sandeau Jacques (b) (2004) Health in the armies. The organisation of the Service and the hospitals. Great figures and harsh realities (part two). Review of Napoleonic Remembrance 450: 27-37.

6. Museum of the Army Health Service (2016) personal communication, Paris.

7. Inter-university Health Library (2010) personal communication, Paris.

8. Marchioni J (2003) The role of Sir Larrey, surgeon of the Imperial Guard. Actes Sud (ed.), Arles.

9. Ferret-Dussart Karine (2004) Maxillofacial surgery throughout history. Glyphe (ed.), Paris.

10. Riaud Xavier (a) (2012) Napoleon $1^{\text {st }}$ and his doctors, L'Harmattan (ed.), Medicine throughout the centuries Collection, Paris.

11. Lemaire Jean-François (1992) Napoleon and medicine. François Bourin (ed.), Paris.

12. Lemaire Jean-François (2003) Napoleonic medicine, Nouveau Monde/Fondation Napoléon (ed.), Paris.

13. Gourdol Jean-Yves (2010) Baron Dominique Larrey (1766-1842), French military surgeon, Baron of the Empire 1-16.

14. Soubiran André, Le Baron Larrey (1966) Napoleon's surgeon, Fayard (ed.), Paris

15. Larrey DJ (1812) Memoirs on Military Surgery and Campaigns. Volume II, Paris.

16. Larrey DJ (1829-1836) Surgical clinic practiced notably in the camps and military hospitals from 1792 to 1829 , Paris, Baillière.

17. desaix.unblog.fr, Desaix, 2008.

18. Haegele Vincent (2015) Murat, Perrin (ed.), Paris.

19. Woodforde J (1968) The strange story of false teeth, Routledge \& Kegan Paul (ed.), Londres.

Copyright: (C2018 Riaud X. This is an open-access article distributed under the terms of the Creative Commons Attribution License, which permits unrestricted use, distribution, and reproduction in any medium, provided the original author and source are credited. 